\title{
The Cell Cycle, Cell Death, and Cell Morphology during Retinoic Acid-Induced Differentiation of Embryonal Carcinoma Cells
}

\author{
C. L. Mummery, ${ }^{1}$ C. E. van Den Brink, P. T. van der SAag, and S. W. DE LaAT \\ Hubrecht Laboratory, International Embryological Institute, Uppsalalaan 8, 3584 CT Utrecht, The Netherlands
}

Received December 5, 1983; accepted in revised form March 1, 1984

\begin{abstract}
Time-lapse films were made of PC13 embryonal carcinoma cells, synchronized by mitotic shake off, in the absence and presence of retinoic acid. Using a method based on the transition probability model, cell cycle parameters were determined during the first five generations following synchronization. In undifferentiated cells, cell cycle parameters remained identical for the first four generations, the generation time being 11-12 hr. In differentiating cells, with retinoic acid added at the beginning of the first cycle, the first two generations were the same as controls. The duration of the third generation, however, was increased to $15.7 \mathrm{hr}$ while the fourth and fifth generation were approximately $20 \mathrm{hr}$, the same as in exponentially growing, fully differentiated cells. The increase in generation time of dividing cells was principally due to an increase in the length of $S$ phase. Cell death induced by retinoic acid also occurred principally in the third and subsequent generations. Cell population growth was then significantly less than that expected from the generation time derived from cycle analysis of dividing cells. Cells lysed frequently as sister pairs suggesting susceptibility to retinoic acid toxicity determined in a generation prior to death. Morphological differentiation, as estimated by the area of substrate occupied by cells, was shown to begin in the second cell cycle after retinoic acid addition. These results demonstrate that as in the early mammalian embryo, differentiation of embryonal carcinoma cells to an endoderm-like cell is also accompanied by a decrease in growth rate but that this is preceded by acquisition of the morphology characteristic of the differentiated progeny.
\end{abstract}

\section{INTRODUCTION}

The study of malignant, murine teratocarcinoma offers promise for the analysis of two complex biological phenomena, namely early mammalian development and neoplasia. Insight into the process of embryogenesis may be gained since the teratocarcinoma stem cells, or embryonal carcinoma (EC) cells, have been shown to resemble the inner cell mass (ICM) cells of the blastocyst in their developmental potential and to provide a suitable model for studying certain aspects of early mammalian development (for review, see Graham 1977; Hogan, 1977; Martin, 1975; Heath, 1983). Likewise, tumorigenesis may be studied in EC cells since their immediate differentiated progeny are nonmalignant (for reviews, see Strickland, 1981; Heath, 1983; Gardner, 1983).

One of the most potent and widely used inducers of differentiation in populations of EC cells is retinoic acid (Strickland and Mahdavi, 1978; Schindler et al., 1981). Addition of this vitamin A derivative at low concentrations to a variety of $\mathrm{EC}$ cell lines, results in a dramatic change in phenotype with cells becoming greatly flattened and their rate of growth reduced (Strickland and Mahdavi, 1978; Schindler et al, 1981; Rosenstraus et al., 1982; Rayner and Graham, 1983). Following such treatment PC13 EC cells, used in the present study, acquire

\footnotetext{
${ }^{1}$ To whom correspondence should be addressed.
}

many characteristics of endoderm of early postimplantation mouse embryos (Adamson et al, 1979; Adamson, 1982). Although it is known that the decrease in growth rate in exponentially growing cells following retinoic acid addition occurs after a lag period and is not due to selection processes (Rayner and Graham, 1983), the relationship between changes in cell cycle parameters and emergence of the differentiated phenotype has not yet been established (reviewed by Hogan et al, 1983).

In the present study we have followed individual PC13 cells by time-lapse cinematography for five generations from the time of retinoic acid addition in order to gain insight into this relationship during early differentiation. We have successfully used such methods previously in murine neuroblastoma cells to investigate the cell cycle dependence of growth regulation by the plasma membrane and the relationship with terminal differentiation (for reviews, see de Laat and van der Saag, 1982a,b; de Laat et al, 1982). PC13 cells are well suited for cell kinetic experiments because they have a relatively short generation time and little tendency to form aggregates, while cells in mitosis can easily be distinguished from cells in other phases by their spherical shape. They can be synchronized easily by mitotic shake off. Determination of cell cycle parameters from the distribution of intermitotic times of sister cells, using the modified transition probability model (van Zoelen et al., 1981) showed that a lag period of two cell cycles 
occurred before parameters characteristic of differentiated cells were adopted. Cell death induced by retinoic acid showed a lag period of similar duration. The flattened phenotype characteristic of differentiated cells on the other hand, was already evident during the second cell cycle after retinoic addition. The results indicate that morphological changes precede changes in cell cycle kinetics during differentiation and imply that although the morphology may effect changes in growth rate, the reverse is unlikely to be the case. The potential of the system as a model for precise determination of the relationship between growth regulation, morphological differentiation, and the emergence of differentiationspecific markers are discussed.

\section{MATERIALS AND METHODS}

Cell culture and differentiation. PC13 clone MA2, a gift from J. K. Heath, Oxford, were grown on gelatinized tissue culture flasks in equal proportions of Dulbecco's modified Eagle's medium and Ham's F12 medium with 5\% fetal calf serum (FCS) and buffered with $\mathrm{NaHCO}_{3}$ $(44 \mathrm{mM})$ in a $5 \% \mathrm{CO}_{2}$ atmosphere. EC cells were subcultured by low-temperature trypsinization using $0.125 \%$ (w/v) trypsin, $50 \mathrm{mM}$ ethylene diaminetetraacetic acid (EDTA) in $\mathrm{Ca}^{2+}, \mathrm{Mg}^{2+}$-free phosphate-buffered saline (PBS) as described by Heath and Deller (1983). Cells were used up to passage 25 . To induce differentiation, $3 \times 10^{6} \mathrm{EC}$ cells were inoculated into a $150-\mathrm{cm}^{2}$ culture flask containing $25 \mathrm{ml}$ of the growth medium described above, $1 \times 10^{-6} M$ all-trans-retinoic acid (RA, added from $10^{-2} M$ stock solution dissolved in dimethyl sulphoxide (DMSO) and stored at $-70^{\circ} \mathrm{C}$ ) and $2 \mu \mathrm{g} / \mathrm{ml}$ polybrene (added from $200 \mu \mathrm{g} / \mathrm{ml}$ in PBS stored at $4^{\circ} \mathrm{C}$ ) (Heath et al, 1981). After incubation for 5 days at $37^{\circ} \mathrm{C}$, cells were trypsinized as above and replated as required. This procedure for differentiation resulted in approximately 1 in $10^{4}$ residual EC cells, as assessed by counting EC colonies 3 days after replating.

Cell synchronization. For synchronization by mitotic shake off, $12 \times 10^{6}$ cells were inoculated in a $150-\mathrm{cm}^{2}$ gelatinized tissue culture flask in growth medium and incubated for $24 \mathrm{hr}$ at $37^{\circ} \mathrm{C}$. The medium was then replaced by $5 \mathrm{ml}$ of growth medium buffered with Hepes $(15 \mathrm{mM})$ and $\mathrm{NaHCO}_{3}(18 \mathrm{mM})$ and pregassed in a $2 \%$ $\mathrm{CO}_{2}$ atmosphere to $\mathrm{pH}$ 7.4. The flask was then shaken manually yielding approximately $1.5 \times 10^{6}$ mitotic cells in suspension as large single cells.

Cell cycle analysis. For analysis of exponentially growing, nonsynchronized cultures EC cells were plated at a density of $4000 \mathrm{cells} / \mathrm{cm}^{2}$ in $25-\mathrm{cm}^{2}$ culture flasks in $5 \mathrm{ml}$ of growth medium buffered with Hepes and $\mathrm{NaHCO}_{3}$ pregassed in $2 \% \mathrm{CO}_{2}$ as above. After growth for one generation, retinoic acid and polybrene were added as required and filming commenced immediately, using a frame interval of 12 or $20 \mathrm{~min}$. Filming of fully differentiated cultures (PC13 END) was commenced 24 $\mathrm{hr}$ after replating, as above, in the absence of retinoic acid and polybrene.

For analysis of synchronized cultures, mitotic cells were plated at a density of 4000 cells $/ \mathrm{cm}^{2}$ in $25-\mathrm{cm}^{2}$ culture flasks in pregassed growth medium buffered as above, with or without the addition of retinoic acid and polybrene. Within $30 \mathrm{~min}$, cells had attached and divided into two cells. The appearance of cell pairs was designated time zero, and filming was commenced.

Films were analyzed using a method described by van Zoelen et al. $(1981 \mathrm{a}, \mathrm{b})$ based on the transition probability model of Smith and Martin (1973) (see Appendix I for details). Values for the intermitotic times $\left(T_{\mathrm{i}}\right)$ of sister cells were obtained directly from time-lapse films. Values of $\lambda$, the transition probability could then be determined from the plot of the logarithm of the fraction of cells having an intermitotic time larger than or equal to a given time $t$ as a function of $t$ (the $\beta$ plot; Appendix I).

From the values of $T_{\mathrm{i}}$ and $\lambda$, values could be calculated (Appendix II) for the other cell cycle parameters namely the duration of the $B$ phase $\left(T_{B}\right)$, the duration of the $A$ state $\left(T_{\mathrm{A}}\right)$, the generation time $\left(T_{\mathrm{g}}\right)$ and an upper limit for the fraction of cells in the A state $\left(\phi_{\mathrm{L}}^{\mathrm{A}}\right)$.

DNA synthesis. DNA synthesis was measured as the amount of $\left[{ }^{3} \mathrm{H}\right]$ thymidine $\left(\left[{ }^{3} \mathrm{H}\right] \mathrm{TdR}\right.$; sp act $55 \mathrm{Ci} / \mathrm{mmole}$, final concentration $0.5 \mu \mathrm{Ci} / \mathrm{ml}$ ) incorporated during a 30 -min pulse at $37^{\circ} \mathrm{C}$, into the cellular fraction insoluble in ice-cold trichloroacetic acid, essentially as described previously (Mummery et al, 1981).

Cell surface area. During differentiation EC cells in monolayer flatten and increase the area they occupy. In order to quantify this process, the area obtained by tracing around the periphery of cells in enlarged timelapse films (scale $18 \mu \mathrm{m} / \mathrm{cm}$ ) was determined, using a Wang digitizer connected to a Wang 2200 minicomputer. Measurements were made on synchronized cells (30 per time point) every $2 \mathrm{hr}$ for approximately four generations.

\section{RESULTS}

\section{Nonsynchromized, Exponentially Growing Cells}

Effects on retinoic acid on proliferation. Values for intermitotic times were determined for exponentially growing PC13 stem cells (PC13 EC) and their differentiated progeny (PC13 END or endoderm) directly from time-lapse films, as described under Materials and Methods. PC13 END were assessed as differentiated on morphological criteria for the purposes of film analysis but parallel experiments showed that such cells had other properties which confirmed their differentiated 
nature; immunofluorescence showed that the cells no longer bound antibodies against the SSEA- 1 and Forssman antigens (from P. Stern, Oxford) found on EC cells, while the fibrin/agar overlay method (Beers et al., 1975) clearly indicated that they produced plasminogen activator (results not shown). Having shown that the modified transition probability model is indeed appropriate for describing the kinetics of proliferation of $\mathrm{PC} 13$ cells (Appendix II), the other principal cell cycle parameters, listed under Materials and Methods, were determined. These are shown in Table 1.

The cell generation time $\left(T_{\mathrm{g}}\right)$ is clearly almost doubled in the differentiated cells, the increase being almost entirely due to a larger $T_{\mathrm{B}}$, the transition probability $(\lambda)$ by comparison being only slightly reduced. Nevertheless, it was sufficiently reduced to result in the parameter $\phi_{\mathrm{L}}^{\mathrm{A}}$, an upper limit for the fraction of cells in the A state being slightly increased by differentiation and the duration of the A state to increase. There was, however, no significant redistribution of cells over the various phases of the cell cycle, not more than $10 \%$ of cells being in the A state under the conditions used in both the stem and differentiated cell cultures. The cell cycle parameters and differentiated phenotype remained constant in the absence of retinoic acid for at least two cell generations (not shown), a stability also found by others (Rayner and Graham, 1983). The life span of the differentiated cells in vitro, as for many nontumourigenic cells in culture was, however, limited and they could not be serially passaged.

Some insight into the rate at which the cell generation time increases after induction of differentiation can be gained by following individual EC cells in exponentially growing, nonsynchronized cultures from the time they receive retinoic acid. Under these conditions, cells may

TABLE 1

Cell Cycle Parameters in Exponentially Growing PC13 EC AND PC13 END CELLS

\begin{tabular}{lrr}
\hline & PC13 EC & PC13 END \\
\hline Generation time, $T_{\mathrm{g}}(\mathrm{hr})$ & $11.62 \pm 0.11$ & $19.60 \pm 0.54$ \\
Transition probability, $\lambda\left(\mathrm{hr}^{-1}\right)$ & $1.43 \pm 0.12$ & $0.73 \pm 0.05$ \\
Fraction of cells in the A state, $\phi_{\mathrm{L}}^{\mathrm{A}}$ & $0.08 \pm 0.01$ & $0.09 \pm 0.01$ \\
Duration of B phase, $T_{\mathrm{B}}(\mathrm{hr})$ & $10.93 \pm 0.11$ & $18.23 \pm 0.52$ \\
Duration of A state, $T_{\mathrm{A}}(\mathrm{hr})$ & $0.70 \pm 0.08$ & $1.36 \pm 0.15$ \\
Number of cell pairs analyzed & 43 & 60 \\
\hline
\end{tabular}

Note. Parameters obtained from comparison of the intermitotic times of sister cells, as described under Materials and Methods. Exponentially growing cultures of PC13 END cells were obtained by exposing PC13 EC cells for 5 days to retinoic acid $\left(1 \times 10^{-6} M\right)$ and polybrene $(2 \mu \mathrm{g} / \mathrm{ml})$, then replating at $8000 \mathrm{cells} / \mathrm{cm}^{2}$ in the absence of inducers for $24 \mathrm{hr}$ before filming was commenced. Values given as mean $\pm \mathrm{SE}$. first be exposed to retinoic acid during any phase of the cell cycle. Determination of the intermitotic times of sister cells first requires that a cell divides. For cells in early $G_{1}$ phase at the time of retinoic acid addition for example, up to one generation may have passed before determinations of cell cycle parameters can commence. Nonetheless, the mean intermitotic times of the first three complete cell cycles following retinoic acid addition were measured and found to be $12.50 \pm 0.50,16.56 \pm 0.77$, and $22.68 \pm 1.21 \mathrm{hr}$ (mean $\pm \mathrm{SEM} ; n=18)$, respectively. There is clearly a lag period before the mean intermitotic time increases to the value in exponentially growing PC13 END cells, although the precise duration of the lag period cannot be determined in nonsynchronized cultures.

\section{Synchronized Cells}

Determining the mean generation time in cultures distributed randomly in the cell cycle at the time of retinoic acid addition as above inevitably means that any cell cycle dependence for the duration of the lag period will be masked. PC13 EC cells can, however, be synchronized by mitotic shake off (Rayner and Graham, 1983). We have taken advantage of this property to follow more precisely the effects of retinoic acid as a function of the cell cycle after induction. As for exponentially growing PC13 EC and PC13 END cells, the validity of applying the transition probability model to synchronized cells was first confirmed (Appendix II).

(i) Proliferation of stem cells after synchronization. Cell cycle parameters were determined from time-lapse films of synchronized cells for five complete cycles following shake off, as shown in Table 2. For the first four cell cycles, the parameters remain constant and differ only slightly from those in exponentially growing cells shown in Table 1. Only in the fifth generation, when the culture substrate is completely full, does the generation time of the EC cells $\left(T_{\mathrm{g}}\right)$ increase somewhat due, principally, to an increase in $T_{\mathrm{B}}$.

(ii) Effect of retinoic acid. Retinoic acid was added to synchronized PC13 EC cells at the time mitotic cells were replated (time zero) and the cell cycle parameters again determined for the first five generations. These values are shown in Table 3. Clearly the duration of the first two cell cycles after synchronization is unaffected by the presence of retinoic acid, all parameters having values within error equal to those in control cultures. This is confirmed, at least in the first cell cycle, by determination of $\left[{ }^{3} \mathrm{H}\right] \mathrm{T} d \mathrm{R}$ incorporation. Figure 1 shows that retinoic acid has no immediate effect on the rate of DNA synthesis in the cell cycle. In addition, it shows that DNA synthesis begins 1 to $2 \mathrm{hr}$ after plating, approximately the duration of the A state; the period of 
TABLE 2

Cell Cycle Parameters in Synchronized PC13 EC Cells

\begin{tabular}{|c|c|c|c|c|c|}
\hline & \multicolumn{5}{|c|}{ Generation } \\
\hline & First & Second & Third & Fourth & Fifth \\
\hline Transition probability, $\lambda\left(\mathrm{hr}^{-1}\right)$ & $1.55 \pm 0.35$ & $1.51 \pm 0.17$ & $1.95 \pm 0.20$ & $1.48 \pm 0.08$ & $1.19 \pm 0.21$ \\
\hline Fraction of cells in A state, $\phi_{\mathrm{L}}^{\hat{A}}$ & $0.07 \pm 0.01$ & $0.07 \pm 0.01$ & $0.06 \pm 0.01$ & $0.08 \pm 0.01$ & $0.08 \pm 0.01$ \\
\hline Duration of B phase, $T_{B}(\mathrm{hr})$ & $11.94 \pm 0.16$ & $11.86 \pm 0.14$ & $11.05 \pm 0.11$ & $11.19 \pm 0.12$ & $13.82 \pm 0.11$ \\
\hline
\end{tabular}

Note. Parameters obtained from comparison of the intermitotic times of sister cells, as described under Materials and Methods. Time zero was taken as the time when two sister cells appeared from one large mitotic cell. Determinations were made as a function of the generation following synchronization by mitotic shake-off. Values given as mean $\pm \mathrm{SE}$.

DNA synthesis occupies the greatest part of the cell cycle, so that $T_{\mathrm{B}}$ consists predominantly of $\mathrm{S}$ phase. In the third cycle following retinoic acid addition, however, the rate of cell cycle progression is significantly reduced. As in the exponentially growing, nonsynchronized cultures (Table 1), this is principally due to an increase in $T_{B}$, i.e., lengthening of $S$ phase with no change in the fraction of cells in the $A$ state (predominantly the $G_{1}$ phase) or in the probability of an $A / B$ phase transition. Only in the fourth and fifth cycles after retinoic acid addition, are cell cycle parameters the same as those in exponentially growing PC13 END cells (Table 1) adopted. In these cell cycles the major contribution to the increase in generation time was again an increase in $T_{\mathrm{B}}$. There was also, however, a minor but significant increase in the duration of the A state with a decrease in $\lambda$ in the fourth cell cycle. Cells were relatively more difficult to follow as pairs in the fifth cell cycle due to cell death (see below) and high local densities, so that analysis was based on less data. The error in $\lambda$ in this cycle is greater than in all others, so the significance of the higher value (Table 3, column 5 ) is reduced.

\section{Cell Death}

From the generation time derived from analysis of dividing cells $\left(T_{\mathrm{g}}\right)$ above, a prediction can be made for the rate of increase in the cell population. Alternatively, a value for the apparent generation time $\left(T_{G}\right)$ can be calculated from the increase in cell number per photo frame with time (van Zoelen et al, 1981; Mummery et al., 1983). For exponentially growing cultures, $N_{t}$ $=N_{0} \cdot e^{k t}$ where $N_{t}$ and $N_{0}$ are the cell numbers at times $t$ and zero, respectively, and $k$ is a constant; $t=T_{\mathrm{G}}$ when the population has doubled i.e., $N_{t}=2 N_{0}$. If all cells divide and actively contribute to the growth of the population then $T_{\mathrm{g}}=T_{\mathrm{G}}$. Cases where $T_{\mathrm{g}}<T_{\mathrm{G}}$ suggest the presence of a nondividing fraction of the population. The number of cells per frame as a function of time after synchronization is shown for PC13 cells in Fig. 2. Without retinoic acid (Fig. $2 \mathrm{~A}$ ) the cell number increases initially in a stepwise manner with the cells remaining synchronous for about four cell cycles. From leastsquares analysis of these points, a value for $T_{\mathrm{G}}$ was calculated using the above equation. For cells without

TABLE 3

Cell Cycle Parameters in Synchronized PC13 EC Cells following Addition of Retinoic Acid

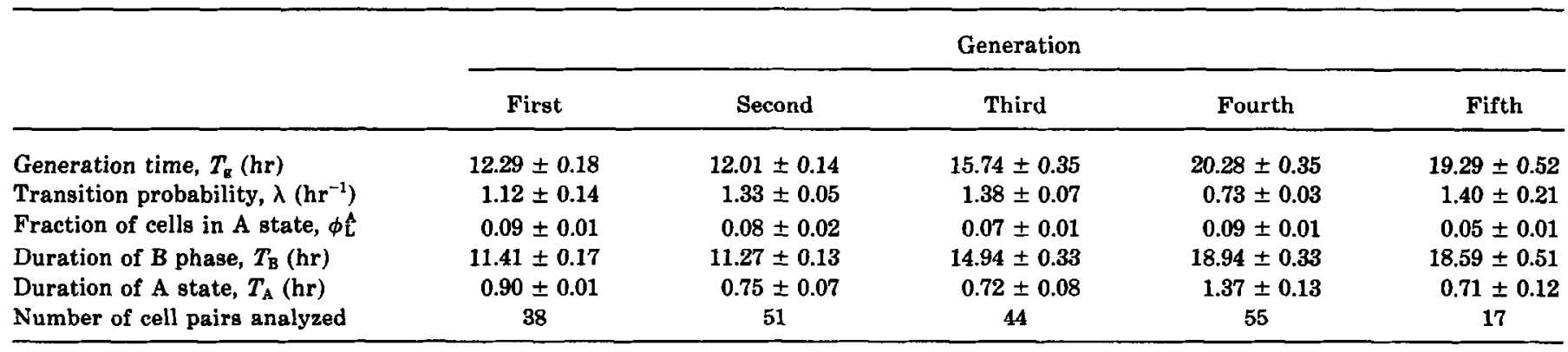

Note. Parameters obtained from comparison of the intermitotic times of sister cells, as described under Materials and Methods. Retinoic acid $\left(10^{-6} M\right)$ and polybrene $(2 \mu \mathrm{g} / \mathrm{ml})$ were added at the beginning of the first cell cycle at time zero (see legend to Table 2 ). Values given as mean $\pm \mathrm{SE}$. 


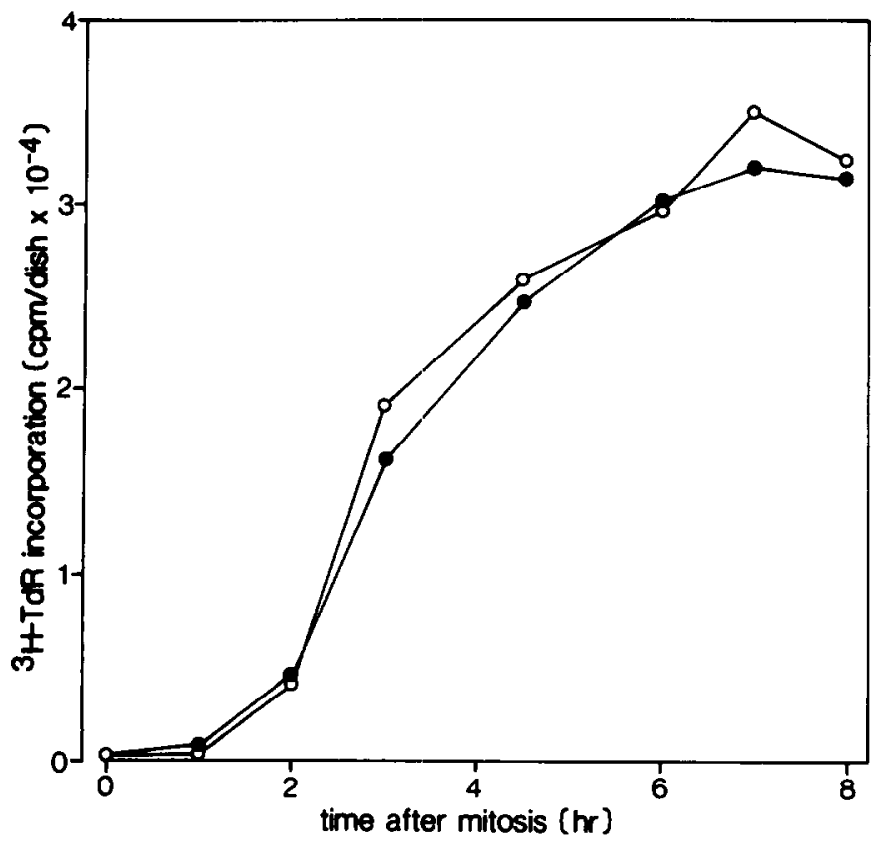

FIG. 1. Effect of retinoic acid $\left(10^{-6} \mathrm{M}\right)$ on DNA synthesis during the first cell cycle following synchronization of PC13 EC cells. Cells were incubated for $30 \mathrm{~min}$ in DMEM-FCS containing $0.5 \mu \mathrm{Ci} / \mathrm{ml}$ $\left[{ }^{8} \mathrm{H}\right] \mathrm{TdR}$ as described under Materials and Methods. Control $(\mathrm{O})$ and with retinoic acid addition of $t=0(\bullet)$. Each point in three-fold.

retinoic acid this was $14.5 \pm 0.5 \mathrm{hr}$ until the culture surface was full with $\mathbf{4 0 0}$ cells/frame (frame area $\mathbf{0 . 3 5}$ $\mathrm{mm}^{2}$ ) after approximately $50 \mathrm{hr}$. This is of the same order as that obtained from the intermitotic times of sister cells despite the approximation introduced by considering the stepwise increase linear (Fig. 2). Further, it demonstrates that the majority of cells participate in the proliferation process, i.e., there is little cell death or spontaneous differentiation. When retinoic acid is added at time zero (Fig. 2B) the initial increase in cell number per frame gives an apparent generation time of $14.9 \pm 0.6 \mathrm{hr}$, again of the same order as that obtained from the intermitotic times of sister cells over the first $30 \mathrm{hr}$. Thereafter, however, at nonconfluency, the apparent generation time becomes $73.7 \pm 3.0 \mathrm{hr}$, almost four times that of PC13 END cells (Table 1). Thus although there appears to be no acute toxic effect of retinoic acid, with little cell death during the first two cycles following addition, significant cell death does occur during the third and subsequent cycles. Further, sister cells appeared to lyse within a short period of one another. Of 73 sister pairs followed in time-lapse films during the third cell cycle following retinoic acid addition, $49 \%$ survived until the fourth generation; in $19 \%$ of the pairs one cell only lysed while in $30 \%$ both sister cells lysed and then in the same or adjacent frames (i.e., within $20 \mathrm{~min}$ of each other). There was no evidence of a viable, nondividing subpopulation of cells in retinoic acid-treated cultures, which might have contributed to the high apparent generation time. This high level of cell death is, however, not a general characteristic of differentiated cells; the increase in cell number/frame gives an apparent generation time of $33.0 \pm 1.5 \mathrm{hr}$ for PC13 END cells (not shown) in the absence of retinoic acid, significantly less than that observed during retinoic acid treatment although still somewhat higher than that obtained from the intermitotic times of sister cells (see Table 1). There was no evidence of dedifferentiation in PC13 END cells in the absence of retinoic acid.

\section{Cell Surface Area during Differentiation}

One of the most obvious differences between PC13 EC and PC13 END cells is the extremely flattened morphology and greater attachment to the substrate of the latter compared with the former (Fig. 3). In order to investigate the relationship of the morphology with the changes in cell cycle parameters described above, we have determined the area of substrate occupied by cells as a function of the cell cycle during differentiation. The results are shown in Fig. 4. The variations in area of cells in the first cell cycle are apparently unaffected

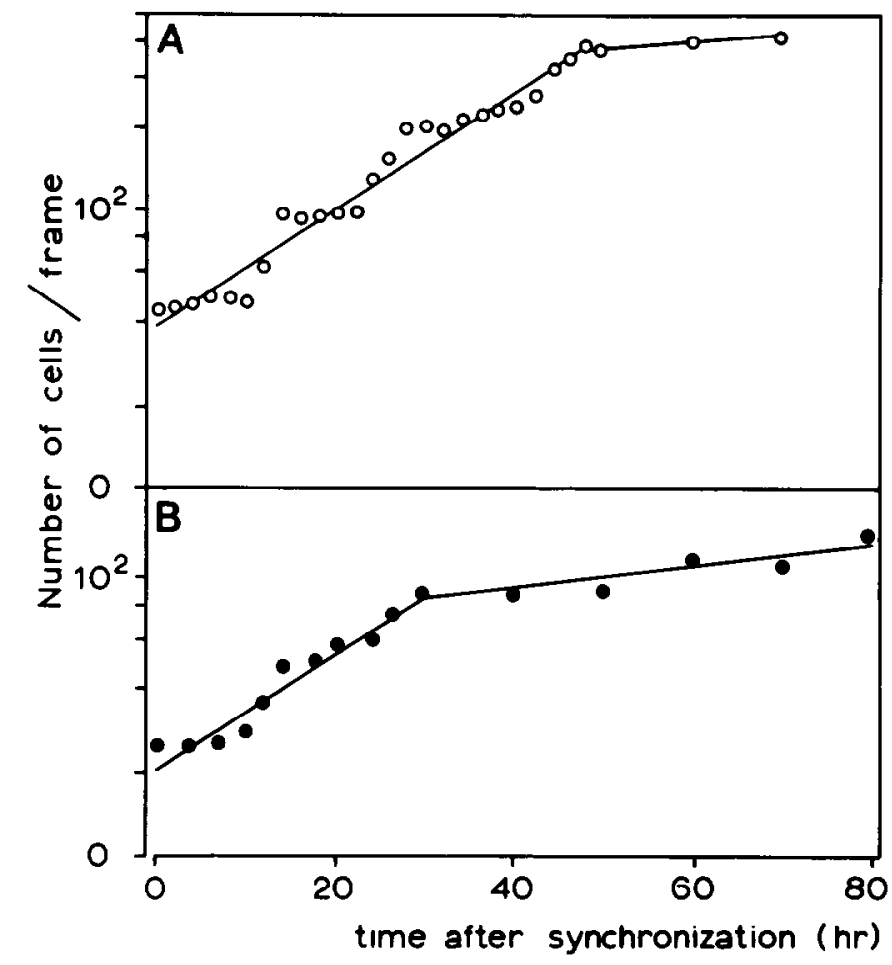

FIG. 2. Effect of retinoic acid on the increase in cell number/photo frame in synchronized PC13 EC cells. Cell number/photo frame was determined every $2 \mathrm{hr}$ on time-lapse films for which cell cycle parameters are shown in Tables 2 and 3 . The area of each photo frame was $0.35 \mathrm{~mm}^{2}$. (A) Without retinoic acid, (B) with retinoic acid addition at time zero. 


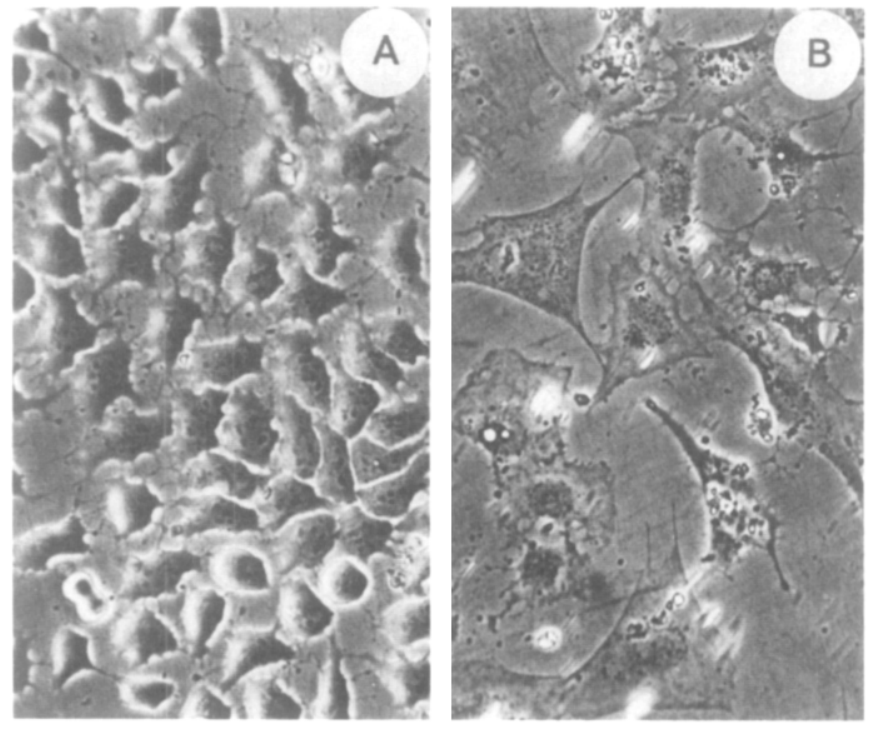

FIG. 3. Effect of retinoic acid treatment after four cell cycles on the morphology of PC13 EC cells. (A) Control cells, (B) cells to which retinoic acid was added at time zero after synchronization.

by the presence of retinoic acid. In the second cell cycle, however, morphological changes in terms of a greater area occupied on the substrate are clearly induced by retinoic acid, despite the rate of cell cycle progression being unaffected. At the end of the second cycle the average area occupied by each cell returns to the value at time zero. The maximum area occupied by cells in the presence of retinoic acid then increases consistently with each subsequent cell cycle. This is in contrast to PC13 EC cells without retinoic acid, which actually oc- cupy a smaller area as the cell density increases. It would thus appear that morphological changes precede changes in growth rate during differentiation and that the acquisition of the flattened phenotype is a progressive process, occurring stepwise during the subsequent cell cycles rather than occurring suddenly during one specific cycle. Between the second and third cycles in the presence of retinoic acid, the area of substrate occupied does not return to initial values completely. This may be due to some desynchronization or the greater overlap of these two cycles compared with the first and second. There is clearly a relationship between the increase in area of substrate occupied and subsequent cell death following retinoic acid treatment. Of 20 cells in the second cell cycle which survived the next division, 10 lysed during the course of the third cell cycle. The area these cells occupied on the substrate during the second cell cycle ( $18 \mathrm{hr}$ after synchronization) was 282 $\pm 11 \mu \mathrm{m}^{2}$ (mean $\pm \mathrm{SE}$ ) compared with $334 \pm 16 \mu \mathrm{m}^{2}$ for cells surviving to the fourth cycle. It was thus possible to predict at an early stage the descendents of which cells would eventually form the PC13 END cell population.

\section{DISCUSSION}

The present study has shown that retinoic acid-induced differentiation of PC13 embryonal carcinoma cells to cells resembling endoderm significantly reduces their rate of growth due principally to an increase in the length of time individual cells spend in $\mathbf{S}$ phase. A lag period of two complete cell cycles was observed before

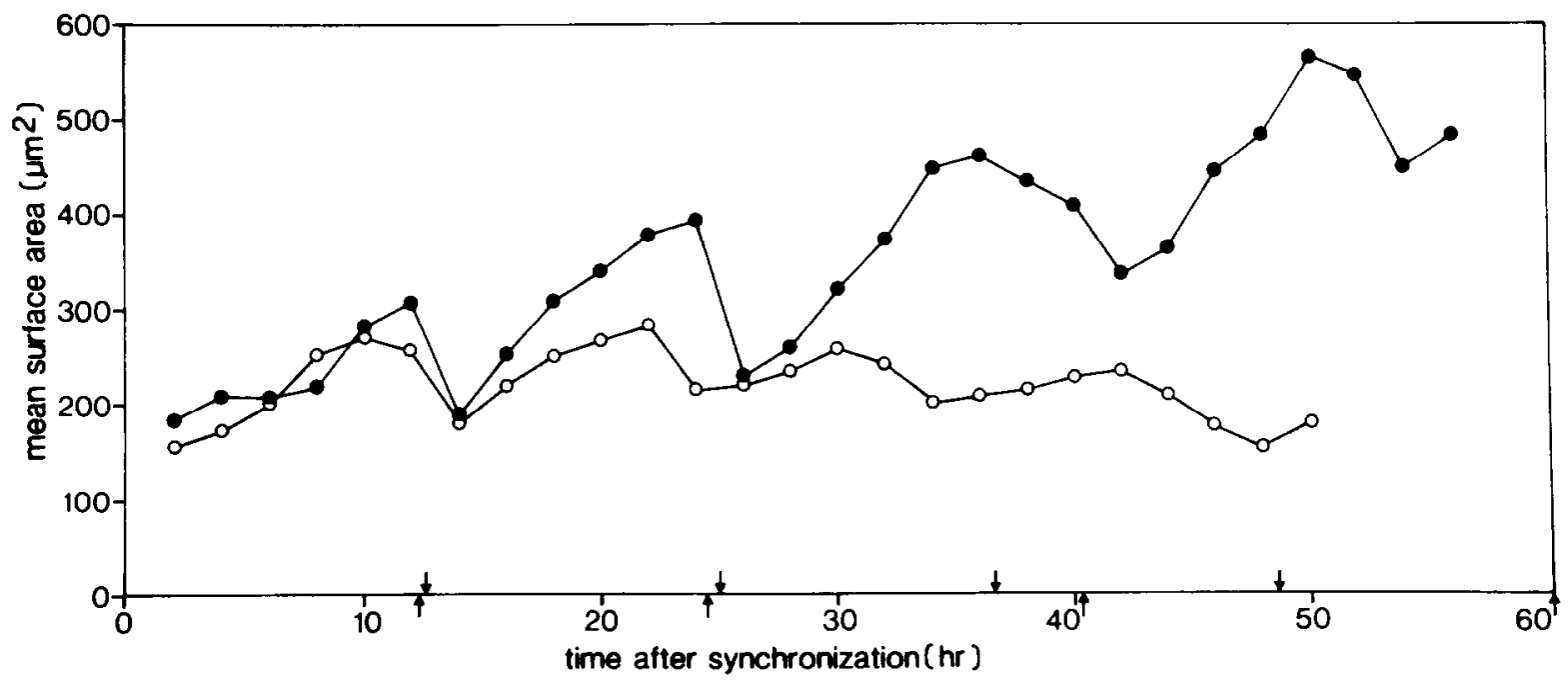

FIG. 4. Effect of retinoic acid on the area of substrate occupied by cells as a function of time after synchronization. As shown in Fig. 4, PC13 cells acquire an extremely flattened morphology. The rate at which this occurs was followed by digitizing the area of cells from timelapse films. Control $(O)$ and with retinoic acid $(\bullet)$. Each point represents the mean of the area occupied by 30 cells. The error was $\leqslant 5 \%$ for all points. The arrows on the coordinate indicate the average times of division of synchronized EC cells, with (below line) and without (above line) RA. 
changes in cell cycle parameters occurred. Morphological changes and the acquisition of the extremely flattened phenotype characteristic of endoderm was, however, already evident after a lag of only one cell cycle. Cells which acquired the flattened cell morphology during the second cell cycle generally survived the toxic effects of retinoic acid, their descendents forming the differentiated cell population, while cells which flattened less rapidly often only survived one more division before lysing. That cells frequently lysed as sister pairs might suggest that cells become committed to die in the generation prior to lysis.

In the undifferentiated state, measurement of the rate of DNA synthesis showed that PC13 EC cells have an extremely short $G_{1}$ phase, in agreement with results of others in different EC lines (Linder et al,, 1981; Rosenstraus et al., 1982) and indeed in cells of the preimplantation mouse embryo (Ganow and Prescott, 1970; Luthardt and Donahue, 1975; Mukherjee, 1976; Sawicki et al, 1978). Cells in cleavage stages of embryos of a wide range of animal species have even been shown to have cycles lacking a $G_{1}$ period entirely (reviewed Prescott, 1976).

The transition probability model (Smith and Martin, 1973) with a single random transition within the cycle described the proliferation of PC13 cells, provided biological variation within the culture was assumed in the system parameters $\lambda$ and $T_{\mathrm{B}}$, which increased with decreasing family relationship (van Zoelen et al., 1981a,b). The value of the transition probability $(\lambda)$ for both PC13 EC and PC13 END cells was high compared with, for example, that found by Brooks et al. (1980) in Swiss 3T3 and CHO cells $\left(\lambda=0.3-0.9 \mathrm{hr}^{-1}\right)$, but comparable with that found in C1300 neuroblastoma cells, clone Neuro2A (van Zoelen et al, $1981 \mathrm{a}$; Mummery et al, 1982). Although differentiation was accompanied by a small decrease in value of $\lambda$ and an increase in the duration of the A state, the overall contribution of this to the increase in generation time was minimal. Rosenstraus et al. (1982) have shown that the reduction in the rate of growth following differentiation in another EC cell line resulted largely from an increase in the duration of $S$ phase, although $G_{1}$ phase was also significantly longer. Based upon these results, it seems reasonable to suggest that during differentiation of PC13 cells, an increase in the length of $S$ phase, rather than late $G_{1}$, makes the greatest contribution to the increase in generation time. Regulation of growth phenotype during early differentiation by variation in the length of $S$ phase is not only observed in EC cells but also in the mouse embryo itself (Solter et al, 1971). This contrasts with the regulation of terminal differentiation where the alteration in growth rate results principally from changes in the length of $G_{1}$ phase (Prescott, 1976).
The extensive flattening, which occurs during differentiation is not only characteristic of PC13 cells but also of a variety of other EC cell lines including F9 (Strickland and Mahdavi, 1978) and OC15 S1 (Wartiovaara et al, 1978) and the endoderm of the mouse embryo (for review, see Hogan et al, 1983). The cause of the flattening is, however, not yet known. A change in cell shape points to a reorganization in one or more of the following: the cytoskeletal elements, synthesis of matrix glycoproteins, and the mode of attachment to the substrate. Although changes in all three of these parameters have been reported, evidence has been obtained from different EC cell lines, all distributed heterogeneously in the cell cycle so that it remains disparate. Synchronized populations of EC cells present a potential means of solving the disparity, and a line such as PC13 which remains synchronous for several generations presents the first well characterized system for such measurements.

A contentious issue in developmental biology is whether, in some instances, a change in the differentiated state of a cell is dependent on some prior cell cycle event. Holtzer et al. (1975) have postulated a "quantal" cell cycle as the critical event that gives a daughter cell having metabolic options different from those of the immediate precursor. PC13 EC cells require the presence of retinoic acid for $24 \mathrm{hr}$ (two cell cycles) before being "committed" to the differentiation pathway (Rayner and Graham, 1983) and on morphological criteria it is possible to predict after one cycle which cells will form the differentiated population. The behavior of PC13 cells during differentiation is therefore compatible with the concept of a quantal cell cycle between induction and the expression of chromosome regions in daughter cells not available for transcription in the mother cells.

To what extent the morphological and biochemical changes observed during retinoic acid-induced differentiation of EC cells are the result of differentiation itself or are a side effect of retinoic acid treatment is not yet clear. It is known, for example, that retinoids can inhibit (Jetten et al, 1979; Lotan, 1980; Jetten, 1980) and stimulate (Dicker and Rozengurt, 1979; Schroder et $a l ., 1980)$ growth, induce differentiation, and suppress the expression of the transformed phenotype in a variety of malignant cells other than EC cells (see Lotan et al., 1983). Growth inhibition of, for example, Swiss 3T3 cells by retinoic acid has been attributed specifically to a lengthening of S phase (Rapaport et al., 1981), as in PC13 cells. In addition, although PC13 END cells bind and respond to epidermal growth factor (EGF) and PC13 EC cells do not (Rees et al., 1979), similar increases in EGF binding are observed in Balb/c 3T6 mouse fibroblasts treated with retinoic acid (Jetten, 1982). However, in the majority of the non-EC cell lines the effects of 
retinoic acid are reversible, while for EC cells, the differentiated phenotype and biochemical markers are retained even in the absence of retinoic acid (Table 1). This would argue against "differentiation" of otherwise nullipotent EC by retinoic acid being an artifact introduced by the inducer.

From the time-lapse films, it was evident that the treatment of this clone of $\mathrm{PC} 13$ cells by retinoic acid does not result in the selection of a subpopulation of differentiated cells already present in the stem cell culture (see also Rayner and Graham, 1983). Selection in another form may occur, however, since only part of the population appears susceptible to retinoic acid toxicity while the other part continues to proliferate with the characteristics of the fully differentiated progeny. It is unclear whether susceptibility to retinoic acid toxicity is a stochastic process or whether PC13 clones are heterogeneous with respect to susceptibility. A heterogeneous response has been frequently observed in a number of morphologically homogeneous EC cell lines, in particular in the binding of a variety of antisera including monoclonal antibodies, where the proportion of fluorescent EC cells is never 100\% (Artzt et al, 1973; Stern et al, 1975, 1978). It has been suggested that the inability to label all the EC cells with antibody in any of the various lines may be related to a failure of the antigen to be expressed during parts of the cell cycle (see Stern et al, 1978) but the use of synchronized cells in the present study would argue against this as the reason for the heterogeneous response to the toxic effects of retinoic acid. Further investigation including subcloning experiments will be required to clarify this point.

Once differentiated, cells can be maintained in the differentiated state in the absence of retinoic acid for their life span. In such cultures there was a significant difference between the apparent generation time derived by cell counting and the generation time derived from dividing pairs of sister cells in absence of overt cell death. Similarly, Rayner and Graham (1983) have observed little increase in the size of clones of PC13 END cells in the absence of lysis despite DNA synthesis (Heath et al., 1981). To explain this they proposed that differentiated cells may proceed through cycles of endoreduplication in the absence of cytokinesis. Such a mechanism would explain the high value for the apparent generation time in PC13 END cells in the present study.

The present study has clearly shown that the change in growth rate is a relatively late event and is preceded by the morphological changes characteristic of differentiation. Similar results have been found by Rosenstraus et al. (1982), who showed that morphological differentiation was not complete when the changes in cell cycle parameters were measured. It is known that a variety of (biochemical and monoclonal) markers such as the ability to bind EGF (Rees et al., 1979) and secrete plasminogen activator (Strickland and Mahdavi, 1978; Jetten and Jetten, 1979) are expressed upon differentiation. The presence of most of these markers is evident after 1-2 days but little is known of the temporal sequence in which they appear or whether this might be cell cycle related. Synchronized PC13 EC cells thus have great potential use in the attempt to unravel these complex events of early differentiation and establishing the rate at which they occur. Work is currently in progress in this system to trace the appearance of differentiationassociated biochemical and monoclonal markers and conversely the disappearance of markers specific for stem cells. By these means, we hope to gain insight into some of the many questions remaining on the relationship between growth regulation and differentiation.

\section{APPENDIX I}

\section{The Transition Probability Model}

Descriptions of cell cycle kinetics in exponentially growing cultures can be obtained most readily by analyzing the distribution of intermitotic times $\left(T_{i}\right)$ within a culture, as determined from time-lapse films. It has been a general observation that even genetically identical cells show great variability in $T_{\mathrm{i}}$, predominantly by variability in their $G_{1}$ period. Smith and Martin (1973) have proposed a model, the transition probability model, for the cell cycle which is able to describe to a large extent the kinetics of proliferation and the variability in $T_{\mathrm{i}}$. This model consists of a quasi-resting A state comprising part of $G_{1}$ in which cells can stay for a variable period, governed by a constant probability per unit of time $(\lambda)$ of leaving the $A$ state. On leaving the $A$ state, cells traverse a deterministic $B$ phase of constant duration $\left(T_{\mathrm{B}}\right)$ before their daughters reenter the $A$ state. The average $T_{\mathrm{i}}$ and its sample variation are fully determined by the values of $\lambda$ and $T_{\mathrm{B}}$. In this type of analysis the data are usually presented as semilogarithmic plots of (1) the fraction of cells with $T_{i}$ values larger than or equal to a certain time $t$, as a function of $t$ ( $\alpha$ curve), and (2) the fraction of siblings having an absolute difference in $T_{\mathrm{i}}\left(T_{\mathrm{s}}\right)$ larger than or equal to an indicated time $t$, as a function of $t$ ( $\beta$ curve). According to the original single random transition model, $\alpha$ and $\beta$ curves should yield linear and parallel lines with slopes equal to $-\lambda$. The model predicts equality between the mean value of $T_{\mathrm{s}}\left(\bar{T}_{\mathrm{s}}\right)$ and its standard deviation $\left[\operatorname{SD}\left(T_{\mathrm{s}}\right)\right]$ and this has generally been found experimently although some modifications to the model have been proposed to accommodate experimentally observed discrepancies (Brooks et al., 1980). In particular, van Zoelen et al. $(1981 a, b)$ have proposed a modification to account for 
the observation that in some cell types, the mean absolute difference in $T_{\mathrm{i}}$ between cell pairs was found to increase with descending family relationship between the cells, and consequently the slope of $\beta$ curves determined for cell pairs is a function of their relationship (reviewed de Laat and van der Saag, 1982). If the positively skewed, normal distribution of $T_{\mathrm{i}}$ was taken into account, this behavior could be explained simply by postulating a normally distributed variability in $\lambda$ and $T_{\mathrm{B}}$ within the culture (assumed in other models to be negligible), which increases with decreasing family relationship (van Zoelen et al., 1981a,b). Further, the nonlinearity of $\alpha$ - and $\beta$-curves could also be thus explained. This formulation allows for determination of the fraction of cells in the A state $\left(\phi_{\mathrm{A}}\right)$, a useful parameter for comparing kinetic data of cultures under various experimental conditions.

In summary, using this modified transition probability model, various cell cycle parameters can be obtained by determining the intermitotic times $\left(T_{\mathrm{i}}\right)$ of sister cells from time-lapse films, as follows:

$$
T_{\mathrm{B}}=\bar{T}_{\mathrm{i}}-1 / \lambda,
$$

where $\lambda$ is obtained from linear regression analysis of the $\beta$ curve

$$
T_{\mathrm{A}}=T_{\mathrm{i}}-T_{\mathrm{B}} .
$$

The cell culture generation time $T_{\mathrm{g}}$, which is the time required for doubling the number of cells in culture, provided all cells are dividing, is given by

$$
\frac{T_{1 / 2}}{T_{\mathrm{B}}}=\frac{T_{\mathrm{g}}}{T_{\mathrm{B}}}\left(-1+2^{1-T_{\mathrm{B}}} / T_{\mathrm{g}}\right)
$$

in which $T_{1 / 2}=\ln 2 / \lambda$, while an upper limit for the fraction of cells in the A state $\left(\phi_{\mathrm{L}}^{\mathrm{A}}\right)$ is given by

$$
\phi_{\mathrm{L}}^{\mathrm{A}}=\frac{T_{1 / 2}}{T_{\mathrm{g}}} \cdot 2^{T_{\mathrm{B}}} / T_{\mathrm{g}} .
$$

The fraction of cells in the A state approaches $\phi_{\mathrm{L}}^{\mathrm{A}}$ if the time between mitosis and entrance into the $A$ state is negligible compared with the length of the $B$ phase. The mean duration of the A state is given by $1 / \lambda$.

\section{APPENDIX II}

\section{Validity of Using the TRansition Probability Model to Describe Cell CyCle Kinetics of PC13 CELLS}

In order to test the applicability of the transition probability model to the kinetics of $\mathrm{PC} 13$ cell proliferation, the extent to which theoretical predictions of the model were met by experimental data was investigated. As given in Appendix I, the original transition probability model of Smith and Martin (1973) predicts that $1 / \bar{T}_{\mathrm{s}}=$ slope $\beta$ curve $=1 / \mathrm{SD}\left(T_{\mathrm{s}}\right)=\lambda$, where $\bar{T}_{\mathrm{s}}$ is the mean absolute difference in intermitotic time between pairs of cells (see also Brooks et al, 1980; van Zoelen et al, 1981a). In the modified model, van Zoelen et $a$ l. $(1981 a, b)$ have shown that this only applies when differences in intermitotic times between sister cells are compared, since sister cells show negligible variation in the length of $T_{B}$ (see Appendix I). However, if differences in intermitotic time between unrelated cells are compared, the inequality $1 / \bar{T}_{\mathrm{s}}<$ slope $\beta$ curve $<1 / \mathrm{SD}\left(T_{\mathrm{s}}\right)$ should be found, the result of variation in the length of $T_{B}$ within the population. Furthermore, when comparing unrelated cells the slope of the $\beta$ curve, determined by means of least-square analysis in spite of obvious deviations from linearity (see van Zoelen et al., 1981a,b; and Fig. A1), should equal the sample standard deviation in intermitotic times $\operatorname{SD}\left(T_{\mathrm{i}}\right)$ (van Zoelen et al, 1981b). Values of $\bar{T}_{\mathrm{i}}, \operatorname{SD}\left(T_{\mathrm{i}}\right), \bar{T}_{\mathrm{s}}, \operatorname{SD}\left(T_{\mathrm{s}}\right)$, and slope $\beta$ curve were determined experimentally from time-lapse cinematographic analysis of both exponentially growing and synchronized PC13 EC cells, and of their differentiated progeny, PC13 END (or endoderm) obtained by treating PC13 EC cells for 5 days with retinoic acid then replated in its absence for analysis, as described under Materials \& Methods. Figure A1 shows a typical example of an $\alpha$ - and a $\beta$-plot. Parameters derived from such plots are shown in Table A1. The equality of $1 / \bar{T}_{s}$, the slope of the $\beta$ curve and $1 / \mathrm{SD}\left(T_{\mathrm{s}}\right)$ found for pairs of sister cells compared with the inequality $1 / T_{\mathrm{s}}<$ slope of the $\beta$ curve $<1 / \mathrm{SD}\left(T_{\mathrm{s}}\right)$ found for unrelated cells, shows that sister cells of both PC13 EC and PC13 END show a greater relationship to one another than randomly generated pair combinations. Further, as cell

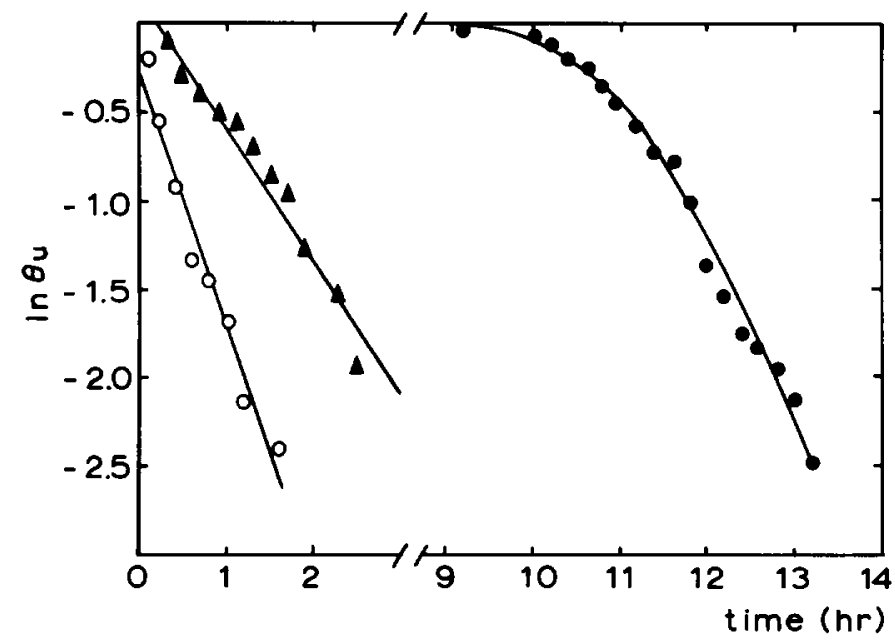

F'IG. Al. Kinetics of PC13 cell proliferation. Typical $\alpha$ curve $(\bullet)$ obtained from 86 intermitotic times; $\beta$ curve $(O)$ derived from 43 pairs of sister cells; $\beta$ curve ( $\wedge$ ) derived from 43 pairs of unrelated cells. $\theta_{u}$ represents the undivided fraction. 
TABLE A1

Effect of Synchronization on the Variation in Intermitotic Time of PC13 Cells

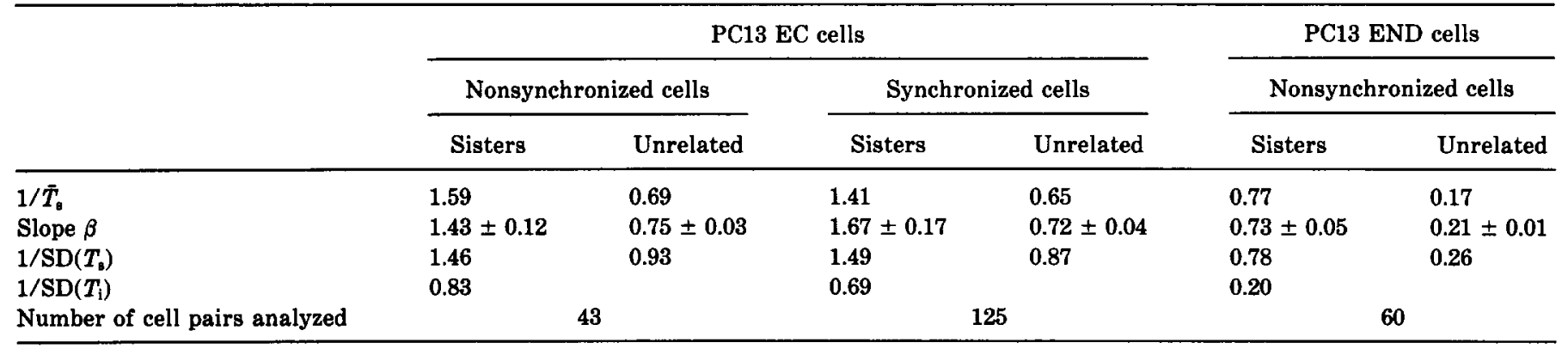

Note. Curves for unrelated cells were generated from random combinations of the intermitotic times of sister cells. Parameters are in dimensions of $\mathrm{hr}^{-1}$.

pairs become less related than sisters, $\operatorname{SD}\left(T_{\mathrm{g}}\right)$ approaches $\mathrm{SD}\left(T_{\mathrm{i}}\right)$. Synchronization by mitotic shake off clearly does not affect the applicability of the model as again the equality is found for sister cells and the inequality for unrelated cells. Further, for randomly generated pair combinations the slope of the $\beta$ curve is in all three cases within error equal to $1 / \operatorname{SD}\left(T_{\mathfrak{i}}\right)$ (Table A1). The predictions of the modified transition probability model are therefore satisfied by both PC13 EC and PC13 END cells so that its application may be considered valid.

This work was supported by grants from Shell Internationale Research Maatschappij B. V. (Shell International Research Cooperation) and the Netherlands Ministry of Housing, Physical Planning and the Environment. We thank Dr. E. J. J. van Zoelen for his advice with the kinetic analysis and critical reading of the manuscript and Ms. E. J. G. M. Hak for secretarial assistance.

Note added in proof. We have recently learned that results similar to those in the present study have also been obtained independently by M. Rayner (Oxford; manuscript in preparation) using different methodology.

\section{REFERENCES}

Adamson, E. D., Gaunt, S. J., and Graham, C. F. (1979). The differentiation of teratocarcinoma stem cells is marked by the types of collagen which are synthesized. Cell 17, 469-476.

ADAMSON, E. D. (1982). The location and synthesis of transferrin in mouse embryos and teratocarcinoma cells. Dev. Biol 91, 227-234.

Artzt, K., Dubois, P., BennetT, T. D., Condamine, H., Babinet, C., and $\mathrm{J}_{\mathrm{ACOB}}$, F. (1973). Surface antigens common to mouse cleavage embryos and primitive teratocarcinoma cells in culture. Proc. Nat. Acad. Sci. USA 70, 2988-2992.

BeERS, W. H., STRICKI.AND, S., and REICH, E. (1975). Ovarian plasminogen activator: Relationship to ovulation and hormonal regulation. Cell 6, 387-394.

Brooks, R. F., BENNETT, D. C., and SMrTH, J. A. (1980). Mammalian cell cycles need two random transitions. Cell 19, 493-504.

DICKER, P., and ROZENGURT, E. (1979). Retinoids enhance mitogenesis by tumour promotor and polypeptide growth factor. Biochem. Biophys. Res. Commun 91, 1203-1210.

Gamow, E. L., and PrescotT, D. M. (1970). The cell life cycle during early embryogenesis of the mouse. Exp. Cell. Res. 59, 117-123.

GARDNFr, R. L. (1983). Teratomas in perspective. Cancer Surveys, 2, 1-19.
GrahaM, C. F. (1977). Teratocarcinoma cells and normal mouse embryogenesis. In "Concepts in Mammalian Embryogenesis" (M. I. Sherman and C. F. Graham, Eds.), pp. 315-394. MIT Press, Cambridge, Mass.

HEATH, J. K., BELL, S. M., and REES, A. R. (1981). The appearance of functional insulin receptors during the differentiation of embryonal carcinoma cells. $J$. Cell Biol 91, 293-297.

HEATH, J. K. (1983). The regulation of embryonal carcinoma proliferation and differentiation. Cancer Surveys, 2, 141-164.

HEATH, J. K., and DeLLER, M. J. (1983). Serum-free culture of PC13 murine embryonal carcinoma cells. J. Cell. Physioh 115, 225-230.

HoGAN, B. L. M. (1977). Teratocarcinoma cells as a model for mammalian development. In "Biochemistry of Cell Differentiation" II. (J. Paul, Ed.), MTP International review of science: Biochemistry series I. University Park Press, Baltimore 15: 333-375.

Hogan, B. L. M., BaRlow, D. P., and Thlly, R. (1983). F9 teratocarcinoma cells as a model for the differentiation of parietal and visceral endoderm in the mouse embryo. Cancer Surveys 2, 115-140.

Holtzer, H., Rubinstein, N., Feluini, S., YeOH, G., ChI, J., Birnbaum, J., and OKAYAMA, M. (1975). Lineages, quantal cell cycles, and the generation of cell diversity. Quart. Rev. Biophys. 8, 523-527.

JETten, A. M., JeTten, M. E. R., Shapiro, S., and Poon, J. (1979). Characterization of the action of retinoids on mouse fibroblast cell lines. Exp. Cell Res. 119, 289-299.

JETTEN, A. M. (1980). Retinoids specifically chance the number of epidermal growth factor receptors. Nature (London) 284, 626-629.

JETTEN, A. M. (1982). Effects of retinoic acid on the binding and mitogenic activity of epidermal growth factor. J. Cell Physiol 110, 235-240.

DE LAAT, S. W., and VAN DER SAAG, P. T. (1982a). The plasma membrane as a regulating site in growth and differentiation of neuroblastoma cells. Int. Rev. Cytol. 74, 1-54.

DE LAAT, S. W., and VAN DER SAAG, P. T. (1982b). Modulation of structure and function of the plasma membrane in the cell cycle of neuroblastoma cells. In "Genetic Expression in the Cell Cycle" Vol. II. (G. M. Padilla and K. S. McCarthy, Sr., Eds.), Academic Press, New York.

de Laat, S. W., Boonstra, J., Moolenaar, W. H., Mummery, C. L., VAN DER SAAG, P. T., and VAN ZOELEN, E. J. J. (1982). Cation transport and growth control in neuroblastoma cells in culture. In "Membranes in Growth and Development" (J. F. Hoffmann, G. H. Giebisch, and L. Bolis, Eds.), pp. 211-236. Liss Inc., New York.

LINDER, S., KRONDAHL, U., SENNERSTAM, R., and RINGERTZ, N. R. (1981). Retinoic acid-induced differentiation of F9 embryonal carcinoma cells. Exp. Cell. Res. 132, 453-460.

LOTAN, R. (1980). Effects of vitamin A and its analogs (retinoids) on normal and neoplastic cells. B. B. A. 605, 33-91. 
LOTAN, R., STOLARSKY, T., and LOTAN, D. (1983). Isolation and analysis of melanoma cell mutants resistant to the antiproliferative action of retinoic acid. Cancer Res. 43, 2868-2875.

LuTHARDT, F. W., and DonoHUE, R. P. (1975). DNA synthesis in developing two-cell mouse embryos. Dev. Biol 44, 210-216.

MARTIN, G. R. (1975). Teratocarcinomas as a model system for the study of embryogenesis and neoplasia. Cell 5, 229-243.

MeEks, R. G., Zaharevitz, D., and Chen, R. F. (1981). Membrane effects of retinoids: possible correlation with toxicity. Arch. Biochem. Biophys. 207, 141-147.

Mitchison, J. M. (1971). The biology of the cell cycle. Cambridge Univ. Press, London.

MukHERJEe, A. V. (1976). Cell cycle analysis and X chromosome inactivation in the developing mouse. Proc. Nat. Acad Sci. USA 73, 1608-1611.

Mummery, C. L., Boonstra, J., VAN DER SAAG, P. T., and DE LAAT, S. W. (1981). Modulation and functional and optimal $\left(\mathrm{Na}^{+}-\mathrm{K}^{+}\right)$ ATPase activity during the cell cycle of neuroblastoma cells. J. Cell Physiol. 107, 1-9.

Mummery, C. L., Boonstra, J., VAn Der SaAg, P. T., and de LaAT, S. W. (1982). Modulation of $\mathrm{Na}^{+}$transport during the cell cycle of neuroblastoma cells. J. Cell. Physiol. 112, 27-34.

Mummery, C. L., VAN DEN BRinK, C. E., Van Der SAaG, P. T., and DE LAAT, S. W. (1983). Screening for cytotoxicity in neuroblastoma cells. II. Growth inhibition: Cell death or impaired cell cycle progression. Toxicol Lett. 18, 211-217.

PrescotT, D. M. (1976). The reproduction of eukaryotic cells. Academic Press, New York.

RaPaport, E., Schroder, E. W., and Black, P. H. (1982). Retinoic acid-promoted expansion of total cellular ATP pools in 3T3 cells can mediate its stimulatory and growth inhibitory effects. $J$. Cell. Physiol. 110, 318-322.

RAYNER, M. J., and GRAHAM, C. F. (1982). Clonal analysis of the change in growth phenotype during embryonal carcinoma cell differentiation. J. Cell Soi 58, 331-344.

Rees, A. R., Adamson, E. D., and Graham, C. F. (1979). Epidermal growth factor receptors increase during the differentiation of embryonal carcinoma cells. Nature (London) 281, 309-311.

Rosenstraus, M. J., Sundeil, C. L., and Liskay, R. M. (1982). Cell cycle characteristics of undifferentiated and differentiating embryonal carcinoma cells. Dev. Biol 89, 516-520.
Sawicki, W., AbramczuK, J., and Blaton, O. (1978). DNA synthesis in the second and third cell cycles of mouse preimplantation development: A cytophotometric study. Exp. Cell. Res. 112, 199-205.

SChINDLeR, J., MATTHAEI, K. I., and SheRMAN, M. I. (1981). Isolation and characterisation of mouse mutant embryonal carcinoma cells which fail to differentiate in response to retinoic acid. Proc. Nat. Acad. Sci. USA 78, 1077-1080.

SCHroDer, E. W., CHOU, I. N., and BlaCK, P. (1980). Effects of retinoic acid on plasminogen activator and mitogenic responses of cultured mouse cells. Cancer Res. 40, 3089-3094.

Smith, J. A., and Martin, L. (1973). Do cells cycle? Proc. Nat. Acad. Sci. USA 70, 1263-1267.

Solter, D., Skreb, N., and Damjanov, I. (1971). Cell cycle analysis in the mouse egg cylinder. Exp. Cell. Res. 64, 331-334.

Solter, D., Shevinsky, L., KNowles, B., and Strickland, S. (1979). The induction of antigenic changes in a teratocarcinoma cell line (F9) by retinoic acid. Dev. Biol. 70, 515-521.

Stancel, G. M., PrescotT, D. M., and Liskay, R. M. (1981). Most of the $\mathrm{G}_{1}$ period in hamster cells is eliminated by lengthening the $\mathrm{S}$ period. Proc. Nat. Acad. Sci. USA 78, 6295-6298.

Stern, P. L., Martin, G. R., and Evans, M. J. (1975). Cell surface antigens of clonal teratocarcinoma cells at various stages of differentiation. Cell 6, 455-465.

Stern, P. L., Willison, K. R., Lennox, E., Galfré, G., Milstein, C., SECHER, D., Ziegler, A., and SPRINGer, T. (1978). Monoclonal antibodies as probes for differentiation and tumor-associated antigens: a Forssman specificity on teratocarcinoma stem cells. Cell 14, 775783.

STRICKLAND, S. (1981). Mouse teratocarcinoma cells: Prospects for the study of embryogenesis and neoplasia. Cell 24, 277-278.

STRICKLAND, S., and MAHDAvi, V. (1978). The induction of differentiation in teratocarcinoma stem cells by retinoic acid. Cell 15, 393403.

WartiovaAra, J., Leivo, I., Virtanen, I., Vaheri, A., and Graham, C. F. (1978). Appearance of fibronectin during differentiation of mouse teratocarcinoma in vitro. Nature (London) 272, 355-356.

van Zoelen, E. J. J., van Der SAAG, P. T., and DE LAAT, S. W. (1981a). Family tree anaysis of a transformed cell line and the transition probability model for the cell cycle. Exp. Cell Res. 131, 395-406.

VAN ZOELEN, E. J. J., VAN DER SAAG, P. T., and DE LAAT, S. W. (1981b) Sources of variation in intermitotic time and their relation to cell cycle kinetics. $J$. Theor. Biol 93, 1037. 